\title{
Learning Vectors (LV): Um Modelo de Avaliação Pro- cessual com Mensuração Não-Linear da Aprendizagem em EaD online
}

Title: Learning Vectors (LV): A Procedural Assessment Model with Non-Linear Measurement of Learning in Distance Education Online

Gilvandenys Leite Sales

Instituto Federal do Ceará

Av 13 de Maio, 2081 - Benfica

Fortaleza/CE

denyssales@ifce.edu.br

\author{
Giovanni Cordeiro Barroso \\ Departamento de Engenharia de Tele- \\ informática - UFC \\ Campus do Pici - Fortaleza/CE \\ gcb@fisica.ufc.br
}

\author{
José Marques Soares \\ Departamento de Engenharia de Tele- \\ informática - UFC \\ Campus do Pici - Fortaleza/CE \\ marques.deti@gmail.com
}

\begin{abstract}
Resumo Este trabalho apresenta um indicador de aprendizagem fundamentado em métricas não-lineares (Fator $\beta$ ) oriundo de um modelo de suporte e gerenciamento à avaliação formativa em EaD online denominado Learning Vectors (LV). O desenvolvimento dos LV envolveu o conceito de vetor e valeu-se de seus componentes bidimensionais para associar o quantitativo e o qualitativo de aprendizagem. A metodologia fundamentada na interação e na mediação por ícones buscou na dinâmica não-linear e em variáveis críticas bipolares, como Positividade/Negatividade (Taxa P/N), semelhantemente ao modelo psicológico-matemático Meta Learning, associar o desempenho do aluno relativamente à sua participação no conjunto de atividades. Implementado no LMS Moodle, esse modelo constitui um recurso qualitativo para acompanhar, avaliar e mediar o processo ensino-aprendizagem.
\end{abstract}

Palavras-Chave: Learning Vectors, Fator $\beta$, Avaliação formativa, EaD, Métricas não-lineares

\begin{abstract}
This paper presents a learning indicator based on nonlinear metric (Factor $\beta$ ) coming from a formative assessment and management model for e-learning support that is called Learning Vectors $(L V)$. The development of $L V$ involved the concept of vector and took advantage of its components to associate the two-dimensional quantitative and qualitative learning. The methodology based on interaction and mediation sought by icons and bipolar critical variables, such as positive/negative variable (Rate P/N), that relates on the nonlinear dynamics model of psychological and mathematical Meta Learning, associated with the student's performance in relation to their participation in all activities. Implemented in LMS Moodle, this model is a qualitative feature to monitor, assess and mediate the teaching-learning process.
\end{abstract}

Keywords: Learning Vectors, Factor $\beta$, Formative assessment, EaD, Nonlinear metrics 


\section{Introdução}

As tecnologias digitais e em rede estão cada vez mais incorporadas à sala de aula, seja na modalidade presencial ou na educação a distância (EaD), como suporte aos espaços pedagógicos de produção do conhecimento. $\mathrm{O}$ emprego dessas tecnologias em apoio às atividades educacionais tem sido sistematizado através de Ambientes Virtuais de Aprendizagem (AVA), que, adicionalmente, proveem recursos para administração, rastreamento de atividades e emissão de relatórios acadêmicos para cobrir os diversos aspectos associados à execução e ao acompanhamento da aprendizagem via EaD online.

Dentre os desafios da EaD online destaca-se a necessidade de implantação de mecanismos de avaliação de aprendizagem capazes de capturar não só os aspectos quantitativos, mas também os qualitativos relativamente à participação e contribuição de alunos em ambientes virtuais.

Embora os AVA apresentem indicadores de desempenho automatizados, em geral, privilegiam-se os aspectos quantitativos, limitando-se a contabilização do número de acessos, registro de interações entre participantes, além de dados e gráficos estatísticos.

Neste trabalho, propõe-se uma contribuição ao processo avaliativo nos ambientes virtuais. Para tanto, foi desenvolvido um instrumento semi-automatizado de avaliação de caráter quali-quantitativo, voltado para uma prática avaliativa contínua, formativa e mediadora do processo ensino-aprendizagem, capaz de auxiliar os aprendizes no gerenciamento de seu desempenho e contribuir para a redução da sobrecarga de trabalho dos Professores/Tutores gerada a partir da análise offline dos muitos arquivos enviados.

O modelo de avaliação proposto, denominado Learning Vectors (LV), é fundamentado na mediação iconográfica e intervenções geradas pelo Professor/Tutor como forma de comunicação com seus alunos, o que pode ajudar a transformar o AVA em um ambiente dialógico e motivador ao permitir maior proximidade no acompanhamento das atividades propostas e o devido tratamento para problemas de aprendizagem ao longo do processo de formação, além de contribuir para suprir a sensação de solidão virtual, que a distância física impõe.

Considerando a sala de aula um sistema dinâmico e não-linear, esse modelo tem sua metodologia complementada por um coeficiente quali-quantitativo denominado Fator $\beta$, que se apresenta como uma métrica pedagógica complexa e não limitada a intervalo de notas entre zero e dez que será detalhado nas próximas seções.

Neste artigo são apresentadas a especificação e a mo- delagem de um indicador de aprendizagem fundamentado em métricas não-lineares, denominado Fator $\beta$, oriundo de um modelo de suporte e gerenciamento à avaliação em EaD online denominado Learning Vectors (LV). Para tanto, está organizado com a seguinte estrutura: na Seção 2 tratam-se dos pressupostos básicos da aprendizagem e avaliação em EaD, apresenta-se o modelo de Avaliação Learning Vectors (LV) e a especificação do Fator $\beta$; na Seção 3 apresenta-se um estudo de caso e faz-se uma análise da relação do Fator $\beta$ com o desempenho do aluno; e, finalmente, na Seção 4, tecem-se as considerações finais.

\section{EaD online: Aprendizagem e Avali- ação}

A aprendizagem é um dos componentes fundamentais em qualquer sistema educacional. Para que se compreenda o papel fundamental das tecnologias e se perceba a relevância das interações propiciadas por essas tecnologias para o sucesso da Educação a Distância $(\mathrm{EaD})$ online, faz-se necessário ter-se, também, uma noção clara sobre aprendizagem e como esta ocorre nesta modalidade de ensino.

Relativo à aprendizagem, a teoria sociocultural de Vigotski estabelece-a como determinante do desenvolvimento do indivíduo e que sua interação com o ambiente social, com toda a sua experiência, história e cultura, ajuda-o no processo de apropriação ou internalização dos objetos culturais desse meio, assim como a desenvolver a sua capacidade cognitiva, cujo potencial pertence ao espaço delimitado pela "Zona de Desenvolvimento Proximal" (ZDP) [1,2].

A ZDP varia de indivíduo para indivíduo e representa o salto entre o que ele domina por si mesmo e aquilo que potencialmente venha a aprender com a ajuda de outro mais capaz. Esses saltos entre os níveis da ZDP, leva a crer numa aprendizagem como processo não-linear e auxiliam o aluno a alcançar crescentes graus de autonomia.

Como espaço pedagógico colaborativo disposto na rede Web para a formação de uma comunidade de aprendizes, têm-se os Ambientes Virtuais de Aprendizagem (AVA), que incluem ferramentas síncronas e assíncronas de interação, a saber: chats, fóruns, wikis, blogs e listas de discussão, dentre outras, que visam o desenvolvimento da autonomia por parte do aprendiz, tomado como ser ativo e gestor de sua aprendizagem.

Com relação à avaliação nestes ambientes, comungase com as ideias de Zabala [3] ao expressar que: “(...) a finalidade da avaliação é ser um instrumento educativo 
que informa e faz uma valoração do processo de aprendizagem seguido pelo aluno, com o objetivo de oportunizar, em todo momento, as propostas educacionais mais adequadas".

A avaliação deve ter, portanto, o caráter de contínua formação. Para Perrenoud [4] uma avaliação formativa é:

Toda prática de avaliação contínua que pretenda melhorar as aprendizagens em curso, contribuindo para o acompanhamento e orientação dos alunos durante todo o seu processo de formação. É formativa toda a avaliação que ajuda o aluno a aprender e a se desenvolver, que participa da regulação das aprendizagens e do desenvolvimento no sentido de um projeto educativo.

Retomar constantemente o processo de aprendizagem é função de uma avaliação contínua e mediadora, não só no ensino presencial, mas também em propostas semipresenciais e a distância. Segundo Hoffmman [5], que defende a realização e retomada de atividades de avaliação frequentes e sucessivas: "A ação avaliativa, enquanto mediação, não se caracteriza como um momento do processo educativo, mas é integrante e implícita a todo processo".

Tomando como pressuposto, então, que um instrumento de avaliação deve informar, regular, formar e oportunizar a aprendizagem em curso, deve-se garantir ao aprendiz um constante feedback as suas ações, fato não observado frequentemente nos atuais AVA.

A falta de acompanhamento do Professor/Tutor e de contínuos retornos para o aluno podem gerar o abandono virtual, o que acarreta a desmotivação e até mesmo a desistência do aprendiz de um curso em EaD online.

No Brasil, os referenciais de qualidade da educação superior a distância [6], especificam que:

“(...) o modelo de avaliação da aprendizagem deve ajudar o aluno a desenvolver graus mais complexos de competências cognitivas, habilidades e atitudes, possibilitando-lhe alcançar os objetivos propostos. Para tanto, esta avaliação deve comportar um processo contínuo, para verificar constantemente o progresso dos alunos e estimulá-los a serem ativos na construção do conhecimento. Desse modo, devem ser articulados mecanismos que promovam o permanente acompanhamento dos estudantes, no intuito de identificar eventuais dificuldades na aprendizagem e saná-las ainda durante o processo de ensino-aprendizagem."

Entretanto, para cumprir as orientações acima expostas, são necessários instrumentos apropriados, algo ainda a ser perseguido nos atuais AVA.

Lopes [7] apresenta uma revisão bibliográfica acerca de instrumentos de avaliação em AVA voltados às interações em atividades colaborativas, e mostra que o paradigma predominante ainda é o quantitativo.

No ambiente virtual interativo, professores e alunos devem construir uma rede e não uma rota, em que os conteúdos de aprendizagem sejam obras abertas à completude com uma dinâmica conectiva e colaborativa [8]. Portanto, deve-se fomentar a interação e a construção compartilhada de saberes.

Na sala de aula online, a avaliação como prática contínua deve promover a qualquer tempo as regulações nas aprendizagens. Para tanto, as ferramentas síncronas ou assíncronas do AVA devem favorecer as ações interventivas e formativas por parte do Professor/Tutor que, interagindo com cada aluno, ou grupos de alunos, proporciona-lhes condições propícias à aprendizagem.

Relativo ao suporte à avaliação qualitativa em AVA, pesquisas de natureza tecnológica buscam suprir o desafio de uma avaliação formativa em $\mathrm{EaD}$ e para o tratamento da sobrecarga de informações geradas nas ferramentas de interação textuais, como a estruturação e a categorização de mensagens. As técnicas empregadas passam pelo monitoramento por multiagentes inteligentes, mineração de dados e rastreamento das ações dos alunos em forma de logs $[7,9,10,11,12,13,14,15,16$, $17,18,19,20,21]$.

Entretanto, tais mecanismos podem trazer dificuldades na hora de computar o resultado das avaliações, por se basearem em análise de muitas informações fornecidas por dados estatísticos, gráficos e mapeamentos de interações, podendo finalizar como um processo manual de avaliação, o que pode tornar cansativa a tarefa do Professor/Tutor, especialmente quando se tem turmas numerosas [22].

Embora estas pesquisas apresentem indicadores de desempenho de qualidade para suporte à avaliação, ainda são necessários mais esforços com o objetivo de atender a uma avaliação formativa em EaD que promova um contínuo acompanhamento online.

Uma possível contribuição seria conceber os processos de avaliação em comunidades virtuais de aprendizagem e toda subjetividade das interações a elas inerentes, inseridos no contexto dos sistemas dinâmicos, e associar na determinação de seus níveis de desempenho, modelos e métricas não-lineares de avaliação.

Um modelo que se enquadra como não-linear é o modelo psicomatemático desenvolvido e validado empiricamente por Marcial Losada [23,24, 25], denominado de modelo Meta Learning (ML). Esse modelo, proposto para avaliar as interações entre equipes de trabalho e entre indivíduos serve para identificar seus comportamentos ou padrões de forma tal a auxiliar na predição de seus desempenhos.

Nesse modelo foi introduzida uma linha divisória definida como Losada Line, uma taxa de positivida- 
de/negatividade (P/N) acima de 2,9 é associada a indivíduos que florescem mentalmente e de alto desempenho.

Na seção a seguir, trata-se de um modelo não-linear aplicado em EaD Online.

\subsection{O Modelo Learning Vectors - LV}

Learning Vectors (LV) [26, 27] é um modelo de suporte e gerenciamento à avaliação formativa concebido para automatizar o acompanhamento qualitativo/quantitativo de alunos em Ambientes Virtuais de Aprendizagem (AVA). Em sua concepção, buscou-se uma metodologia fundamentada na interação e fez-se uso de vetores e de equações trigonométricas na especificação da solução tecnológica.

A opção pelo uso de vetores para a especificação do modelo de avaliação LV reside no fato de que a sua decomposição em componentes ortogonais, determinada pelas projeções sobre eixos cartesianos, mostra que, a esse ente matemático, podem-se associar valores numéricos na forma bidimensional.

A cada uma destas dimensões associam-se aspectos bem definidos que, devidamente trabalhados, mostram-se necessários ao pleno exercício de uma avaliação comprometida com o caráter formativo e de regulagem das aprendizagens.

Esses valores, numa perspectiva de avaliação pertencente a sistemas complexos, dinâmicos e não-lineares, vêm representar a bipolaridade entre as dimensões quantitativa e qualitativa da aprendizagem. Dimensões indissociáveis que se envolvem dialeticamente e se complementam como partes de um todo que em comum visam traçar o perfil e o grau de aprendizagem alcançado pelo aluno.

Epistemologicamente, a metodologia e a construção dos LV referenciam-se em teorias interacionistas sistêmicas, nos caminhos da contínua formação e das regulações das aprendizagens auxiliadas por uma avaliação formativa e na base dos sistemas dinâmicos não-lineares, afinal, trabalhar com a aprendizagem em sala de aula, seja presencial ou virtual, constitui um sistema dinâmico, imprevisível e, muitas vezes, cheio de incertezas.

\subsubsection{LV: Metodologia e Especificação}

O modelo de avaliação proposto pelos LV atua sobre a interação entre os membros do grupo e suas ações sobre o ambiente de aprendizagem. Avaliam-se, em especial, as interações intermediadas por ferramentas específicas, dentre as quais se destacam o fórum de discussão, o debate em salas de chat e os wikis, que permitem a construção colaborativa de documentos.

Completando o conjunto de itens avaliáveis, os LV aplicam-se também sobre as tarefas ou exercícios propostos, que são enviados ao portfólio do AVA de forma individual ou em grupo, bem como armazenam as notas das atividades presenciais, além de gerenciar a frequência do aluno e seu contínuo desempenho e rendimento.

No planejamento de um curso online, agenda-se um conjunto de atividades síncronas ou assíncronas avaliáveis, às quais se atribuem um peso determinado por sua significância, definida por um percentual relacionado à importância da atividade relativamente ao curso como um todo.

Como mecanismo para o acompanhamento das notas e desempenho, tanto por parte do Professor/Tutor como por parte do aluno, utilizam-se de representações geométricas vetoriais, os Vetores-Aprendizagem.

Os Vetores-Aprendizagem representativos das atividades virtuais ou presenciais possuem módulo fixo de 10 unidades. $\mathrm{O}$ componente horizontal $\left(\mathrm{LV}_{\mathrm{x}}\right)$ representa a nota em cada atividade e implica diretamente no rendimento e situação final do aluno. Seu módulo é expresso pela Equação 1:

$$
L V_{x}=10 * \cos (-12 \alpha+I)
$$

em que

- $\alpha=7,5^{\circ}$ é o passo padrão de aprendizagem;

- I é a variável que contabiliza o parâmetro Variação Angular Total do vetor, é função do ângulo $\alpha$ e depende das avaliações atribuídas pelo Professor/Tutor às interações/atividades propostas ao aluno.

A direção dos LV varia discretamente de acordo com a variável I, dada em função do ângulo $\alpha$, que foi selecionado empiricamente por dividir o ângulo de $90^{\circ} \mathrm{em}$ partes iguais. A determinação dos possíveis valores da variação angular é obtida pela Equação 2:

$$
I=\left(\frac{n}{\mathbf{2}}\right) * \alpha,\{n \in N \mid \mathbf{0} \leq n \leq \mathbf{2 4}\}
$$

Os 25 possíveis valores discretos da variável I decorrentes da Eq. 2 facilitaram a especificação dos vetores LV. As correspondentes notas associadas, ao se aplicar na Eq. 1 os valores de I obtidos com a Equação 2, são apresentados na Tabela 1 . 


\begin{tabular}{l|l|l|l|l|l|l|l|l|l}
\hline \multicolumn{1}{c|}{$I$} & Nota & \multicolumn{1}{c|}{ I } & Nota & \multicolumn{1}{|c|}{ I } & Nota & I & Nota & I & Nota \\
\hline $0 \alpha$ & 0,00 & $2,5 \alpha$ & 3,21 & $5 \alpha$ & 6,09 & $7,5 \alpha$ & 8,31 & $10 \alpha$ \\
\hline $0,5 \alpha$ & 0,70 & $3 \alpha$ & 3,83 & $5,5 \alpha$ & 6,59 & $8 \alpha$ & 8,66 & $10,5 \alpha$ \\
\hline $1 \alpha$ & 1,31 & $3,5 \alpha$ & 4,42 & $6 \alpha$ & 7,07 & $8,5 \alpha$ & 8,97 & $11 \alpha$ & 9,81 \\
\hline $1,5 \alpha$ & 1,95 & $4 \alpha$ & 5,00 & $6,5 \alpha$ & 7,52 & $9 \alpha$ & 9,24 & $11,5 \alpha$ & 9,98 \\
\hline $2 \alpha$ & 2,59 & $4,5 \alpha$ & 5,56 & $7 \alpha$ & 7,93 & $9,5 \alpha$ & 9,47 & $12 \alpha$ \\
\hline
\end{tabular}

Tabela 1: Possíveis Valores da Variação Angular Total do Vetor e Correspondentes Valores de Notas

Estabelece-se o limite de $90^{\circ}$ ou $12 \alpha$ para a Variação Angular Total $(\Delta \mathrm{T})$, totalizada na variável I (Equação 3) Assim, o vetor LV fica limitado ao quarto quadrante $\left(-90^{\circ}\right.$ a $\left.0^{\circ}\right)$ :

$I= \begin{cases}\Delta_{T}, & \text { se } \Delta_{T} \leq 12 \alpha \\ 12 \propto, & \text { se } \Delta_{T}>12 \alpha\end{cases}$

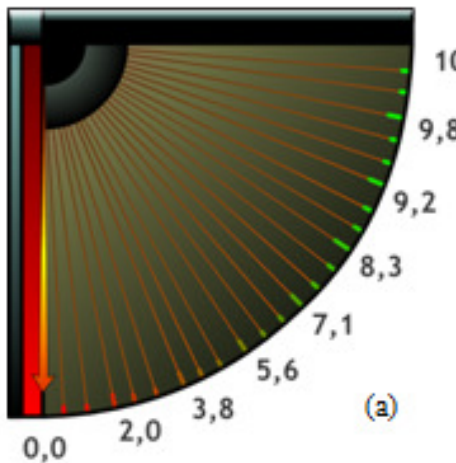

Em sua representação geométrica (Figura 1), o vetor LV inicialmente tem direção que forma um ângulo $\theta=$ $90^{\circ}$ com a horizontal (posição que representa a nota mínima). Os vetores giram em sentido anti-horário, limitando-se a um quadrante de círculo, conforme se avaliam as atividades dos alunos ao longo do curso, indo até $\theta=0^{\circ}$ (posição que representa a nota máxima).

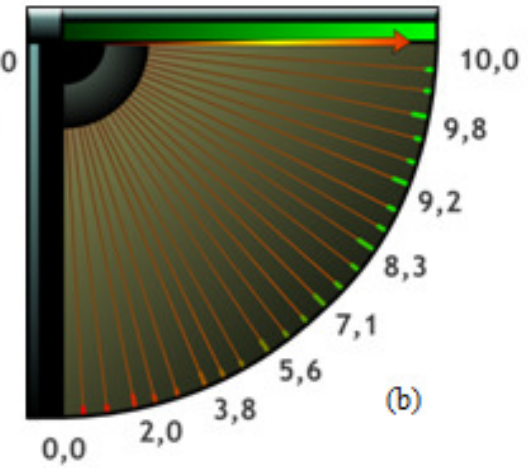

Figura 1: Vetor-Aprendizagem: (a) Nota mínima e (b) Nota máxima

Nesta proposta pedagógica de avaliação, para expressar juízo de valor à mensagem de cada interação/postagem de arquivos que subsidiem as tomadas de decisão e também valorize a subjetividade do processo, o Professor/Tutor usa de uma escala de menções qualitati- vas constituída por seis itens de apreciação: Muito Bom, Bom, Regular, Fraco, Não Satisfatório e Neutro, relacionados a uma escala numérica intitulada Coeficiente do Passo, que é associada a uma escala iconográfica (LV Ícones), cuja correspondência é expressa na Tabela 2.

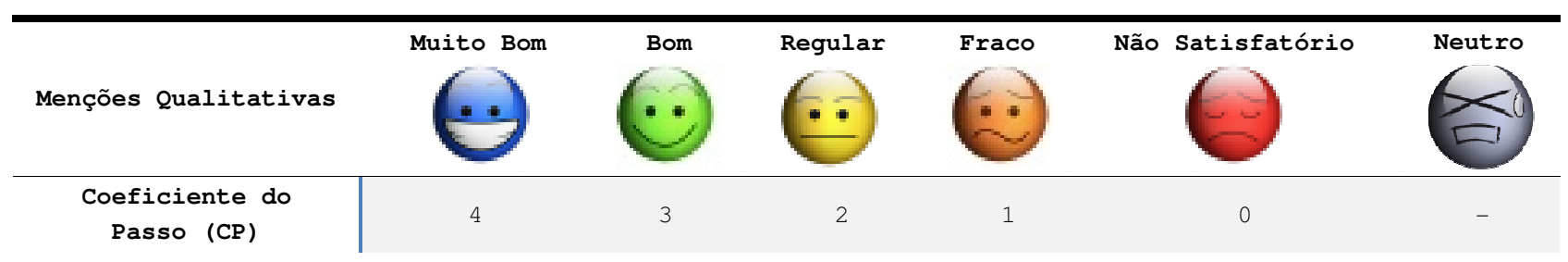

Tabela 2: Escala de Menções Qualitativas e Correspondência Numérica com o Coeficiente do Passo

Os itens de apreciação da Escala de Menções relacionam-se ao nível da interação do aluno (passivo/ativo) e a sua profundidade de reflexão (domínio de conteúdos) exprimindo a subjetividade da avaliação.

O item de apreciação "Neutro" da Escala de Menções permite indicar interações não significativas para avaliação e, além disso, embora não se associe a ele uma variação angular, ele tem por função, assim como os demais itens da escala, de computar a presença do aluno na atividade.

A escala numérica, denominada Coeficiente do Passo (CP), que auxilia na determinação das mudanças discretas de direção do vetor LV, compõe, juntamente com um fator multiplicador $\mathrm{m}$, o múltiplo do ângulo $\alpha$ ao qual se correlaciona cada variação angular sofrida por esse vetor e que resulta nos diversos valores de I expressos na Tabe- 
la 1.

A Variação Angular Total $\Delta_{\mathrm{T}}$ como resultado das intervenções e avaliações efetuadas pelo Professor/Tutor em cada atividade é computada conforme a Equação 4:

$\Delta_{T}=\sum_{i=1}^{n}\left(m * C P_{i}\right) \alpha$,

em que

- $\mathrm{m}$ é um fator multiplicador definido por: $\mathrm{m}=\{\mathrm{x} / 2 ; \mathrm{x} \in \mathrm{N} \mid 1 \leq \mathrm{x} \leq 6\} ;$

- $\quad$ i corresponde à cada interação avaliada;

- $\quad C P_{i}$ é o Coeficiente do Passo, correlaciona-se à menção qualitativa e LV ícone (Tabela 2) atribuído pelo Professor/Tutor às mensagens enviadas ou arquivos anexados pelos alunos.

A matriz de valores resultantes do produto do Fator Multiplicador $\mathrm{m}$ pelo Coeficiente do Passo $\mathrm{CP}$ pode ser visualizada na Tabela 3.

\begin{tabular}{|c|c|c|c|c|c|}
\hline $\begin{array}{c}\mathrm{CP} \\
\backslash \\
\mathrm{m}\end{array}$ & 4 & 3 & 2 & 1 & 0 \\
\hline $1 / 2$ & 2,0 & 1,5 & 1,0 & 0,5 & 0,0 \\
\hline 1 & 4,0 & 3,0 & 2,0 & 1,0 & 0,0 \\
\hline $3 / 2$ & 6,0 & 4,5 & 3,0 & 1,5 & 0,0 \\
\hline 2 & 8,0 & 6,0 & 4,0 & 2,0 & 0,0 \\
\hline $5 / 2$ & 10,0 & 7,5 & 5,0 & 2,5 & 0,0 \\
\hline 3 & 12,0 & 9,0 & 6,0 & 3,0 & 0,0 \\
\hline
\end{tabular}

Tabela 3 - Matriz Produto: Fator Multiplicador (m) X Coeficiente do Passo (CP)

Auxiliado pela primeira coluna da Tabela 3, que corresponde às avaliações com menção "Muito Bom" ou CP $=4$ (LV Ícone Azul), pode-se identificar o número mínimo de interações ou postagens nas ferramentas síncronas ou assíncronas do AVA para que o aluno atinja o máximo de nota numa atividade $\left(\Delta_{\mathrm{T}}=12 \alpha\right.$ ou $\left.90^{\circ}\right)$. Por exemplo, se uma atividade for configurada com $\mathrm{m}=1$, serão necessárias no mínimo três interações por parte do aluno.

O componente vertical do vetor $L V$, denominado $L V_{Y}$ (Figura 1), que se relaciona à negatividade de desempenho, seja para atividades presenciais ou a distância, é dado pela Equação 5:

$L V_{Y}=10 * \operatorname{sen}[(-12 \alpha+I)]$

Por último, para representar a média final do aluno, calcula-se o Quociente de Aprendizagem $\left(\mathrm{LV}_{\mathrm{Q}}\right)$, cujo módulo é dado pela soma dos componentes horizontais de todos os LV envolvidos, ou seja, é a expressão de toda positividade gerada pelo sistema. Esse módulo é o resultado de uma expressão matemática envolvendo todas as atividades do curso com suas devidas ponderações.

Toda vez que o aluno faz o envio de alguma mensagem ou arquivo, utilizando-se das ferramentas de interação Fórum, Chat ou Wiki, aparece a Escala de LV Ícones no AVA para o Professor/Tutor (Figura 2).

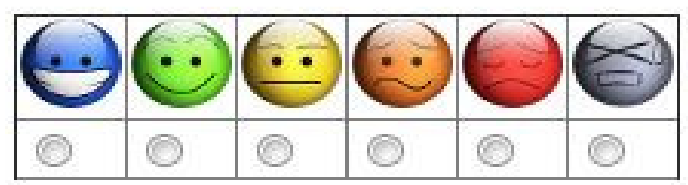

Figura 2: Escala LV Ícones

A interface oferecida pela ferramenta implementada permite ao Professor/Tutor escolher um dos LV Ícones, fazendo sua avaliação da interação ou trabalho do aluno. Por outro lado, a interface permite que somente o aluno responsável pela mensagem ou arquivo enviado tenha acesso ao ícone atribuído pelo Professor/Tutor, o que garante sua privacidade.

Em sua representação geométrica (Figura 1), a projeção horizontal do $\operatorname{LV}\left(\mathrm{LV}_{\mathrm{x}}\right)$ expressa a nota naquela atividade e relaciona-se à positividade de desempenho do aluno. A projeção vertical do $L V\left(L_{y}\right)$ relaciona-se à negatividade do seu desempenho.

A razão entre os fatores positividade/negatividade contribui para a métrica pedagógica não-linear denominada Fator $\beta$, que se relaciona à natureza qualitativa do modelo de avaliação LV. Essa razão envolve os resultados positivos e negativos das contribuições dos alunos nas atividades colaborativas ou individualmente desenvolvidas.

O Fator $\beta$, que relaciona a dimensão bipolar positividade/negatividade (taxa $\mathrm{P} / \mathrm{N})$, pode indicar o nível de desempenho do aluno no curso online.

\subsubsection{O Indicador Qualitativo Não-Linear: Fator $\beta$}

O Fator $\beta$ é um indicador qualitativo não-linear para suporte no acompanhamento da aprendizagem do aluno. O mesmo foi adaptado a partir da dimensão psicológica Positividade/Negatividade (Taxa $\mathrm{P} / \mathrm{N}$ ) do modelo de avaliação de desempenho denominado Meta Learning (modelo ML).

No estabelecimento dos valores padrões de taxa $\mathrm{P} / \mathrm{N}$ para os limites de desempenho do modelo ML, seus autores valeram-se da observação direta do comportamento do indivíduo no grupo, ou contaram com o próprio indivíduo, que respondia quantas emoções positivas ou negativas havia experimentado por dia. 
Como métrica a ser tomada como padrão pedagógico de desempenho de qualidade da aprendizagem online, ora construída de forma partilhada na interação, ora construída por percursos individualizados, o Fator $\beta$ relaciona e associa os aspectos subjetivos tomados a partir dos itens de apreciação da Escala de Menções e transforma-os numa escala formal de avaliação definida por valores que exprimem a positividade em relação à negatividade do desempenho do aluno.

Matematicamente, esse fator, que se relaciona à qualidade do desempenho do aluno no curso, é obtido a partir da seguinte relação trigonométrica (Equação 6):

$\beta=\operatorname{cotg} \phi$, ou: $\beta=\frac{\text { Positividade }}{\text { Negatividade }}=\frac{P}{N}$

As dimensões Positividade/Negatividade estão ilustradas na Figura 3.

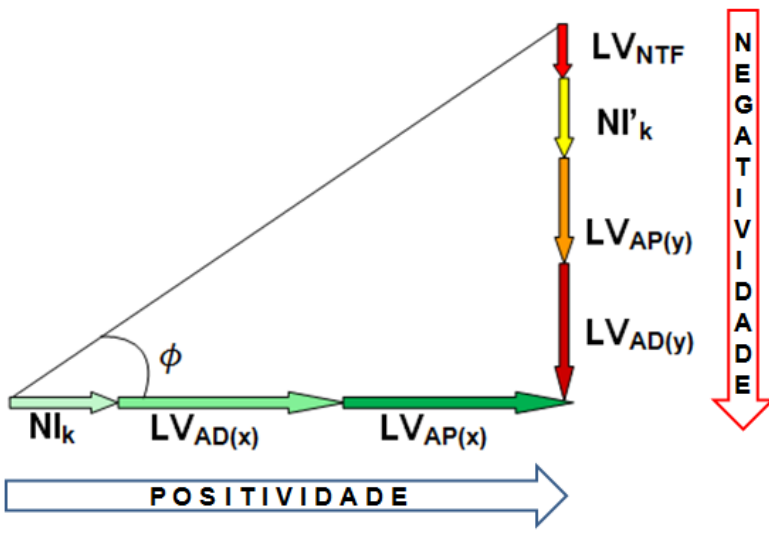

Figura 3: Fator $\beta$ : Positividade $\mathrm{X}$ Negatividade

Toma-se como contribuição positiva, ou Positividade (P), o somatório das projeções horizontais dos LV Fóruns, Tarefas, Chats, Wikis $\left(\mathrm{LV}_{\mathrm{ADx}}\right)$ e Atividades Presenciais $\left(\mathrm{LV}_{\mathrm{APx}}\right)$, sem qualquer ponderação, acrescido do somatório do Número de Interações Positivas $\left(\mathrm{NI}_{\mathrm{k}}\right)$, devidamente ponderadas e contabilizadas nas ferramentas colaborativas, categorizadas com menções qualitativas "Muito Bom" (peso 3), "Bom" (peso 2) ou "Regular" (peso 1), respectivamente correlacionadas aos Coeficiente do Passo (4), (3) ou (2). 7:

O Indicador de Positividade (P) é dado pela Equação

$$
P=\sum_{i=1}^{x} L V_{A D_{i}}+\sum_{j=1}^{y} L V_{A P_{j}}+\sum_{k=1}^{z} N I_{k}
$$

em que:

- $\mathrm{LV}_{\mathrm{ADi}}$ e $\mathrm{LV}_{\mathrm{APj}}$ são, respectivamente, as projeções horizontais dos vetores LV representativos de atividades a distância e atividades presenciais;

- $\quad \mathrm{NI}_{\mathrm{k}}=3 * \mathrm{CP}(4)+2 * \mathrm{CP}(3)+1 * \mathrm{CP}(2)$, são, respectivamente, valores ponderados associados à Escala de Menções com itens de apreciação: "Muito-Bom", "Bom" e "Regular".

Como contribuição negativa, ou Negatividade (N), toma-se o somatório das projeções verticais dos vetores LV Fóruns, Tarefas, Chats, Wikis $\left(\mathrm{LV}_{\mathrm{ADy}}\right)$ e Atividades Presenciais $\left(\mathrm{LV}_{\mathrm{APy}}\right)$, sem qualquer ponderação, acrescido do módulo do $\mathrm{LV}_{\mathrm{NTF}}$ (LV Número Total de Faltas), mais o somatório do Número de Interações Negativas $\left(\mathrm{NI}_{\mathrm{k}}^{\prime}\right.$ ), devidamente ponderadas e contabilizadas nas ferramentas colaborativas, categorizadas com menções qualitativas "Fraco" (peso 1) ou "Não Satisfatório" (peso 2), respectivamente correlacionadas aos Coeficiente do Passo (1) ou (0). 8:

O Indicador de Negatividade (N) é dado pela Equação

$$
N=\sum_{i=1}^{x} L V^{\prime}{ }_{A D_{i}}+\sum_{j=1}^{y} L V_{A P_{j}}^{\prime}+\sum_{k=1}^{z} N I_{k}^{\prime}+L V_{N T F},
$$

em que:

- $\quad \mathrm{LV}^{\prime}{ }_{\mathrm{ADi}}$ e LV' $\mathrm{LPj}_{\mathrm{APj}}$ são, respectivamente, as projeções verticais dos vetores LV representativos de atividades a distância e atividades presenciais;

- $\mathrm{LV}_{\mathrm{NTF}}$ - módulo do LV Número Total de Faltas;

- $\quad \mathrm{NI}_{\mathrm{k}}^{\prime}=1 * \mathrm{CP}(1)+2 * \mathrm{CP}(0)$, respectivamente, valores ponderados associados à Escala de Menções com itens de apreciação: "Fraco" e "Não Satisfatório".

Os valores do Fator $\beta$ obtidos pela Equação 6 com aplicação das equações 7 e 8 serão divididos em intervalos e relacionados a uma escala de menções qualitativas que expressem o grau de desempenho do aluno: Muito Alto, Alto, Médio, Baixo e Muito Baixo. Para tanto, um valor médio do Fator $\beta$ ( $\overline{\text { Fator } \beta}$ ) de cada grupo de alunos deve ser disponibilizado para servir de parâmetro de comparação entre eles.

Fica estabelecido que, independentemente da média obtida e do valor do Fator $\beta$, o aluno é classificado com desempenho "Muito Baixo", caso suas faltas, expressas pelo vetor $\mathrm{LV}_{\mathrm{NTF}}$, tenha módulo superior ao máximo permitido, o que não significa uma reprovação tácita, mas sim um alerta para que se pondere, analise e justifique a ausência do aluno. Para tanto, o sistema permite que se retirem as faltas, devidamente justificadas pelo aluno, em alguma atividade.

Para uma melhor compreensão do suporte à avaliação 


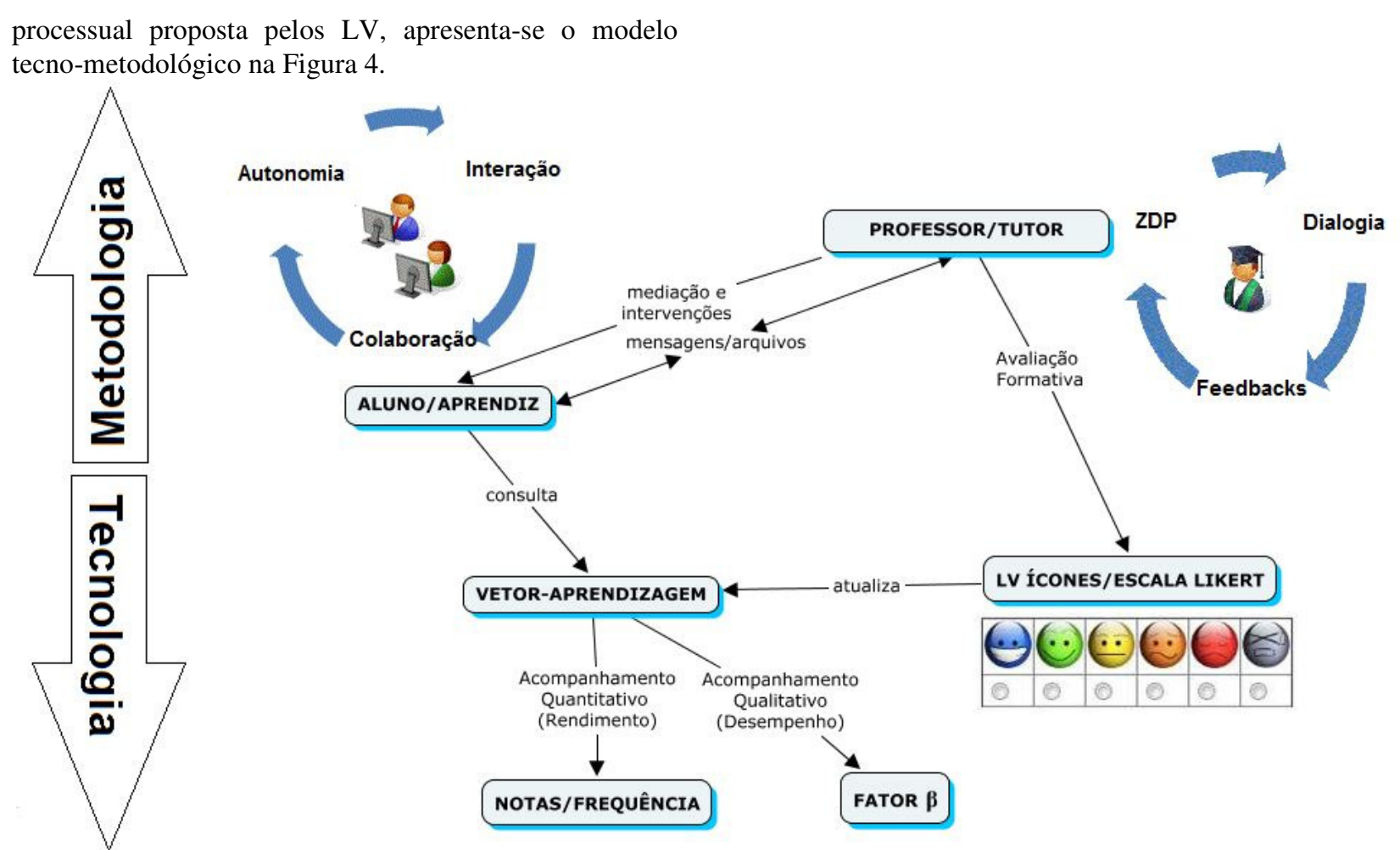

Figure 4: Modelo Tecno-Metodológico de Avaliação Formativa por LV

A implementação, testes e refinamentos dos LV foram feitos como parte de um módulo que se acopla ao ambiente virtual Moodle versão 1.9, que apresenta código-fonte aberto baseado em tecnologia PHP. Por conseguinte, esta foi a linguagem de programação utilizada na implementação dos LV.
O Moodle (Modular Object Oriented Dynamic Learning Environment) é um sistema de gerenciamento da aprendizagem online baseado na filosofia de aprendizagem socioconstrutivista [28], que teve seu desenvolvimento de forma colaborativa em comunidades virtuais a partir de 2001 como um software livre (Figura 5).

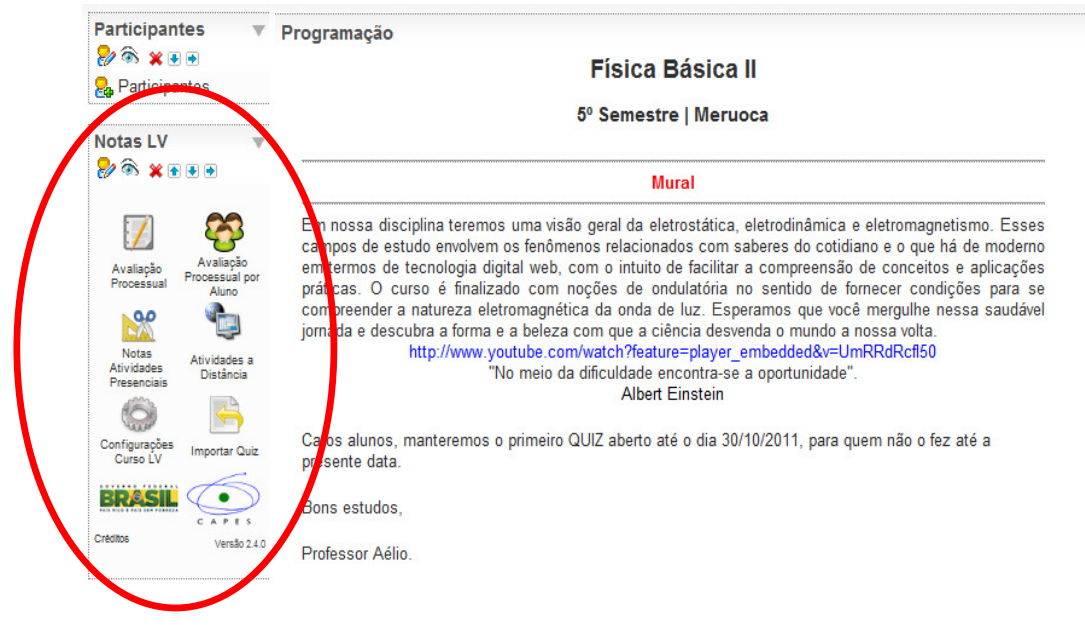

Figure 5: Bloco Learning Vectors no Moodle

Um aspecto a ser realçado nos LV é o fato de ser uma ferramenta de trabalho para Professores/Tutores que possibilita a geração automática de notas ao término da atividade. À medida que ele lê e classifica as mensa- 
gens/arquivos anexados, o sistema automaticamente calcula os escores, o que reduz seu acesso ao curso e sua carga de trabalho destinada às atividades de avaliação.

Como ferramenta de avaliação online, os LV reúnem aspectos qualitativos e quantitativos no acompanhamento da aprendizagem, suas ações coadunam com o princípio da proximidade espacial do design instrucional [29] ao exibir seus feedbacks na mesma tela em que o aluno realiza suas atividades.

Na próxima seção, a partir da integração e aplicação da Metodologia LV e dos Vetores-Aprendizagem em um curso no ambiente virtual Moodle, foi feita uma análise mais detalhada do Fator $\beta$.

\section{O Fator $\beta$ e sua Não-Linearidade}

Os LV foram aplicados com todas as suas funcionalidades nos cursos de Licenciatura em Matemática e Tecnologia em Hotelaria da Universidade Aberta do Brasil (UAB) do Instituto Federal de Educação, Ciência e Tecnologia do Ceará (IFCE).

Ao final do $1^{\circ}$ semestre de aplicação dos LV, com dados já estabelecidos e tabulados, atesta-se a característica da não-linearidade do Fator $\beta$ (Figura 6). Enquanto a linha azul, representativa da nota quantitativa, está linearmente no intervalo fechado de zero a dez, o Fator $\beta$, fator qualitativo não-linear de aprendizagem, representado pela linha vermelha, oscila e rompe os limites desse intervalo ao crescer exponencialmente.

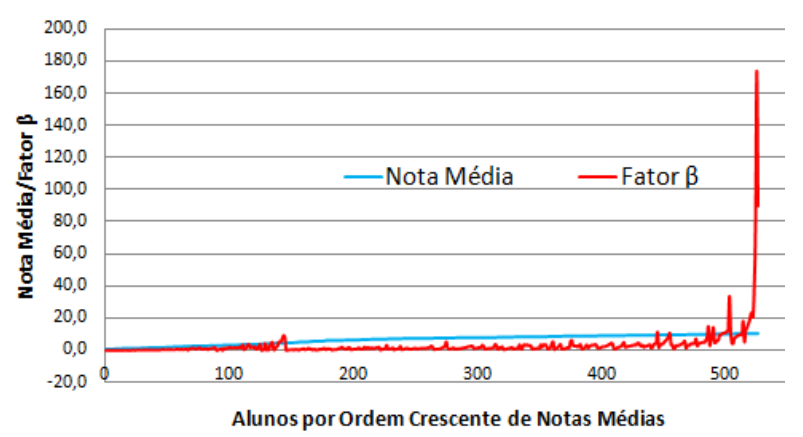

\begin{tabular}{|c|c|c|c|c|c|c|c|c|c|c|}
\hline \multirow{2}{*}{ Alunos } & \multicolumn{2}{|c|}{ TURMA 1} & \multicolumn{2}{|c|}{ TURMA 2} & \multicolumn{2}{|c|}{ TURMA 3} & \multicolumn{2}{|c|}{ TURMA 4} & \multicolumn{2}{|c|}{ TURMA 5} \\
\hline & Média & Fator $\beta$ & Média & Fator $\beta$ & Média & Fator $\beta$ & Média & Fator $\beta$ & Média & Fator $\beta$ \\
\hline 1 & 0 & 0 & 1,8 & 0,64 & 0 & 0 & 0,6 & 0,22 & 1,4 & 0,48 \\
\hline 2 & 0,9 & 0,25 & 2 & 0,75 & 0,3 & 0,08 & 1,3 & 0,49 & 1,6 & 0,54 \\
\hline 3 & 1,8 & 0,67 & 5,3 & 0,34 & 5,9 & 0,56 & 3,6 & 0,64 & 1,7 & 0,62 \\
\hline 4 & 3,6 & 0,1 & 7 & 0,73 & 6,6 & 0,67 & 4,3 & 0,7 & 2,4 & 0,34 \\
\hline 5 & 4,2 & 0,22 & 7 & 1,48 & 7,2 & 0,68 & 5 & 0,84 & 4,4 & 0,55 \\
\hline 6 & 7,1 & 1,22 & 7 & 1,99 & 7,3 & 0,76 & 5,1 & 1,31 & 4,5 & 0,2 \\
\hline
\end{tabular}

Figure 6: Gráfico Representativo da Não-linearidade do Fator $\beta$

Um recorte da amostra fornecida na Figura 6, em que foram selecionadas pouco mais de 100 notas médias finais compreendidas entre sete e dez, possibilita a comparação entre alunos que obtiveram notas iguais (Figura 7).

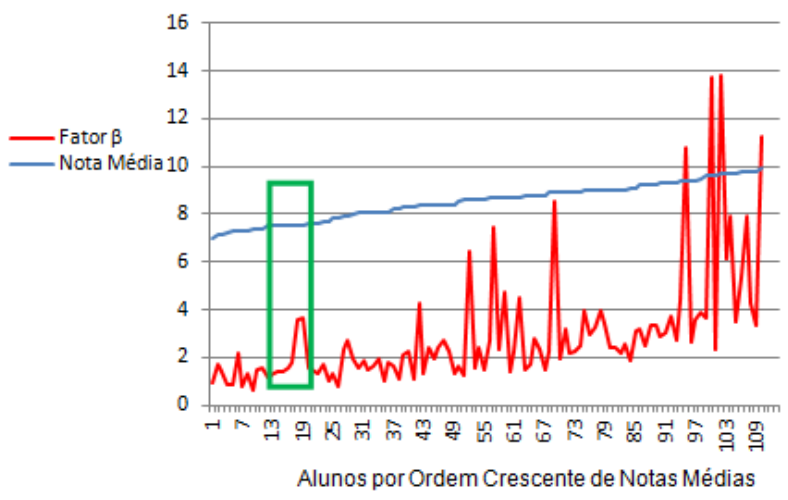

Figura 7: Comparativo do Fator $\beta$ para Alunos com a Mesma Nota Média

Alunos com rendimento expresso por notas médias iguais a 7,50, destacados no retângulo verde da Figura 7, têm Fator $\beta$ diferenciados pela qualidade de seus desempenhos no curso.

\section{1 - Análise do Fator $\beta$ e sua Relação com o Desempenho do Aluno}

$\mathrm{Na}$ Tabela 4, são apresentadas cinco turmas de alunos com seus valores de Médias e Fator $\beta$. Para esse estudo, os dados foram coletados da disciplina Introdução a EaD no primeiro semestre de 2010 em cidades dispersas no estado do Ceará. 


\begin{tabular}{|c|c|c|c|c|c|c|c|c|c|c|}
\hline 7 & 7,2 & 0,74 & 7,1 & 0,7 & 7,3 & 0,74 & 6,4 & 2,33 & 4,6 & 1,27 \\
\hline 8 & 7,6 & 1,26 & 7,1 & 1,03 & 7,4 & 0,97 & 7 & 0,86 & 4,9 & 3,55 \\
\hline 9 & 7,7 & 1,58 & 7,4 & 2,52 & 7,5 & 0,85 & 7 & 3,86 & 5,1 & 0,37 \\
\hline 10 & 7,8 & 1,26 & 7,5 & 2,89 & 7,5 & 1,73 & 7,1 & 0,85 & 5,5 & 0,5 \\
\hline 11 & 7,9 & 1,46 & 7,6 & 2,49 & 7,5 & 0,87 & 7,1 & 1 & 5,6 & 0,62 \\
\hline 12 & 7,9 & 1,54 & 7,7 & 1,39 & 7,6 & 0,89 & 7,5 & 0,86 & 6 & 0,85 \\
\hline 13 & 7,9 & 1,59 & 7,7 & 1,55 & 7,7 & 0,82 & 7,5 & 1,79 & 6 & 0,87 \\
\hline 14 & 8 & 1,35 & 7,9 & 1,16 & 7,8 & 1,46 & 7,6 & 1,46 & 6,1 & 0,73 \\
\hline 15 & 8 & 1,58 & 8 & 1,48 & 7,8 & 1,52 & 7,7 & 1,32 & 6,2 & 0,66 \\
\hline 16 & 8 & 2,17 & 8 & 3,25 & 7,9 & 1,12 & 7,9 & 1,92 & 7 & 1 \\
\hline 17 & 8,1 & 1,69 & 8,1 & 2,16 & 8 & 1,29 & 8,1 & 1,17 & 7 & 1,38 \\
\hline 18 & 8,2 & 1,57 & 8,3 & 1,73 & 8,1 & 1,61 & 8,1 & 1,68 & 7 & 1,54 \\
\hline 19 & 8,2 & 2,28 & 8,4 & 2,34 & 8,2 & 1,78 & 8,6 & 2,25 & 7 & 1,55 \\
\hline 20 & 8,3 & 2,08 & 8,4 & 3,39 & 8,3 & 2,28 & 8,6 & 2,82 & 7,1 & 0,97 \\
\hline 21 & 8,3 & 2,18 & 8,5 & 1,69 & 8,3 & 1,66 & 8,6 & 5,97 & 7,2 & 0,99 \\
\hline 22 & 8,4 & 1,48 & 8,5 & 3,81 & 8,4 & 2,1 & 8,7 & 2,08 & 7,3 & 2,96 \\
\hline 23 & 8,4 & 1,81 & 8,6 & 2,21 & 8,4 & 1,98 & 8,7 & 3,91 & 7,4 & 3,1 \\
\hline 24 & 8,5 & 2,3 & 8,6 & 2,86 & 8,4 & 1,52 & 8,8 & 4 & 7,5 & 3,54 \\
\hline 25 & 8,6 & 2,22 & 8,6 & 3,27 & 8,8 & 2,71 & 8,9 & 3,7 & 7,6 & 1,1 \\
\hline 26 & 8,6 & 2,58 & 8,6 & 8,07 & 8,8 & 2,64 & 9 & 2,21 & 7,7 & 2,01 \\
\hline 27 & 8,7 & 1,04 & 8,7 & 2,49 & 9 & 4,14 & 9 & 6,1 & 7,9 & 3,6 \\
\hline 28 & 8,7 & 1,59 & 8,7 & 11,35 & 9 & 5,91 & 9,1 & 3,17 & 8 & 2,27 \\
\hline 29 & 8,9 & 2,87 & 8,9 & 1,87 & 9,1 & 2,79 & 9,1 & 3,67 & 8 & 2,99 \\
\hline 30 & 9 & 2,44 & 9 & 2,17 & 9,1 & 2,03 & 9,1 & 3,8 & 8,1 & 1,85 \\
\hline 31 & 9,1 & 1,16 & 9 & 2,62 & 9,1 & 4,5 & 9,3 & 3,54 & 8,2 & 2,26 \\
\hline 32 & 9,1 & 2,37 & 9 & 10,27 & 9,2 & 3,27 & 9,3 & 5,54 & 8,3 & 1,99 \\
\hline 33 & 9,1 & 2,49 & 9,1 & 2,76 & 9,2 & 3,42 & 9,3 & 5,71 & 8,3 & 4,83 \\
\hline 34 & 9,1 & 2,83 & 9,1 & 2,78 & 9,3 & 2,68 & 9,3 & 6,38 & 8,4 & 7,46 \\
\hline 35 & 9,2 & 2,64 & 9,1 & 3,28 & 9,4 & 6,57 & 9,4 & 4,85 & 8,5 & 5,86 \\
\hline 36 & 9,2 & 3,39 & 9,2 & 3,36 & 9,5 & 9,1 & 9,4 & 7,14 & 8,7 & 2,87 \\
\hline 37 & 9,4 & 4,17 & 9,2 & 4,84 & 9,5 & 9,0 & 9,5 & 7,63 & 8,7 & 3,55 \\
\hline 38 & 9,5 & 5,48 & 9,2 & 6,7 & 9,6 & 20,15 & 9,6 & 9,71 & 9 & 10 \\
\hline 39 & 9,8 & 4,41 & 9,6 & 9,56 & 10 & 26,25 & 9,6 & 10,75 & 9,1 & 9,77 \\
\hline
\end{tabular}

Tabela 4: Valores de Média e Fator $\beta$ para Alunos da Licenciatura em Matemática UAB/IFCE coletados da Disciplina Introdução a EaD no Semestre 2010.1 em Cidades Dispersas no Estado do Ceará

Para a análise dos dados dessas cinco turmas, traçaram-se gráficos de dispersão com marcadores e, em cada um deles, com o objetivo de interpolar os diversos pontos representativos de Médias e Fator $\beta$, plotaram-se linhas de tendência exponencial e logarítmica na forma de curvas suaves e modeladoras com o auxílio de planilha eletrônica de cálculo. Na Figura 8 apresenta-se a Turma 2 como exemplo. 


\section{Turma 2 - Fator $\beta$ X Média}

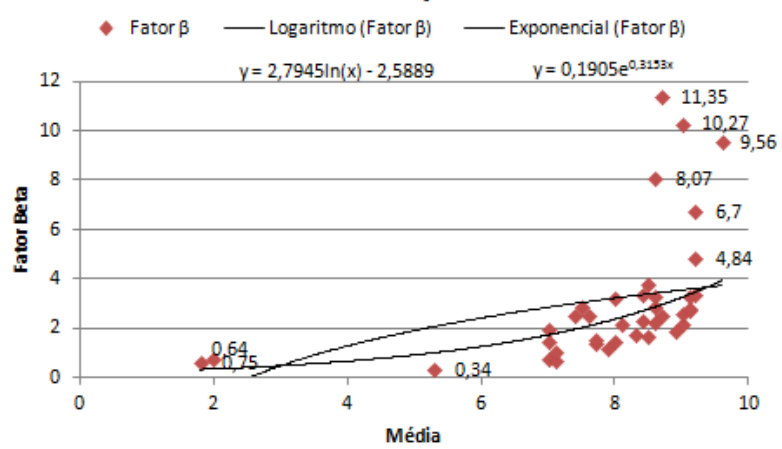

Figura 8: Relação entre Notas Médias e Fator $\beta$ para Turma 2

Em todos os gráficos, definiu-se a assíntota vertical da curva exponencial para $\mathrm{x}=10$. Esse valor também representa o limite superior do domínio de ambas as funções. Em relação à assíntota horizontal da curva logarítmica, com exceção da Turma 1, seu valor aproxima-se gem, verifica-se também uma acentuada inclinação da curvatura da função exponencial.

Observando a simetria dessas funções, suas curvas interceptam-se em pontos que definem um eixo de simetria. Esses pontos podem ser aplicados como limítrofes para da reta definida por $\mathrm{y}=4$, a partir desses valores de ima-

classificação de desempenho do aluno em cada turma.

Com o auxílio de um software de modelagem matemática, determinou-se o valor superior dessa interseção em cada curva.

Ampliando a amostra para as demais disciplinas do semestre, como forma de se definir um valor médio comum, após a coleta de dados e a análise dos respectivos gráficos de notas e Fator $\beta$ de 50 turmas, resolveu-se tomar por base, como critério para classificar o desempenho dos alunos em "Alto" e "Muito Alto", a média dos valores que definem a interseção superior das curvas das funções exponencial e logarítmica.

No momento de gerar as curvas das funções, como forma de delimitar a amostra e refinar a busca por um valor limítrofe, que separa os alunos de desempenho "Alto" e "Muito Alto" dos demais, foram considerados apenas os valores para o Fator $\beta$ abaixo de 10 unidades, uma vez que observações e leituras dos dados dessas 50 turmas possibilitaram concluir que, para esses valores de $\beta$, os alunos já atingem o desempenho "Muito Alto".

$\mathrm{Na}$ Tabela 5, encontram-se os parâmetros das equações que definem as funções que geraram os gráficos de cada uma das 50 turmas e o valor superior comum a cada curva, ou ponto de interseção, para o devido tratamento estatístico.

\begin{tabular}{|c|c|c|c|c|c|}
\hline \multirow{2}{*}{ Turmas } & \multicolumn{2}{|c|}{$\mathbf{y}_{1}=\mathbf{a} * \mathbf{e}^{\mathbf{b}}$} & \multicolumn{2}{|c|}{$\mathbf{y}_{2}=\mathbf{c} * \ln \mathbf{x}+\mathbf{d}$} & \multirow{2}{*}{$\begin{array}{l}\text { Pontos de } \\
\text { Interseção }\end{array}$} \\
\hline & $a$ & $\mathrm{~b}$ & C & $d$ & \\
\hline 1 & 0,1098 & 0,3391 & 1,3064 & $-0,6529$ & 2,19 \\
\hline 2 & 0,1905 & 0,3153 & 2,7945 & $-2,5889$ & 3,67 \\
\hline 3 & 0,0188 & 0,5722 & 2,1884 & $-0,928$ & 3,96 \\
\hline 4 & 0,158 & 0,35 & 2,3014 & $-1,2019$ & 3,89 \\
\hline 5 & 0,1532 & 0,351 & 2,4559 & $-2,0306$ & 3,30 \\
\hline 6 & 0,0878 & 0,4044 & 1,0784 & 1,0423 & 3,42 \\
\hline 7 & 0,264 & 0,2871 & 1,9315 & $-0,1756$ & 4,20 \\
\hline 8 & 0,0293 & 0,49 & 6,1566 & $-11,026$ & 2,62 \\
\hline 9 & 0,0283 & 0,5106 & 1,2353 & $-0,0749$ & 2,62 \\
\hline 10 & 0,0788 & 0,3786 & 1,94 & $-1,9788$ & 2,26 \\
\hline 11 & 0,0188 & 0,5676 & 6,654 & $-11,702$ & 2,76 \\
\hline 12 & 0,2707 & 0,322 & 1,7991 & 0,4646 & 4,34 \\
\hline 13 & 0,1811 & 0,3139 & 1,7223 & $-1,1454$ & 2,52 \\
\hline 14 & 0,2401 & 0,2736 & 1,9181 & $-1,3932$ & 2,83 \\
\hline 15 & 0,1081 & 0,3997 & 1,2985 & 0,7794 & 3,60 \\
\hline 16 & 0,1678 & 0,3119 & 1,6439 & $-0,8192$ & 2,80 \\
\hline 17 & 0,158 & 0,35 & 2,3014 & $-1,2019$ & 3,90 \\
\hline
\end{tabular}




\begin{tabular}{|c|c|c|c|c|c|}
\hline 18 & 0,5368 & 0,1963 & 1,6021 & $-0,3878$ & 3,13 \\
\hline 19 & 0,1192 & 0,3823 & 2,9079 & $-2,9753$ & 3,32 \\
\hline 20 & 0,3446 & 0,2401 & 1,7554 & $-0,5552$ & 3,41 \\
\hline 21 & 0,2199 & 0,2997 & $-1,44$ & 6,8822 & 3,66 \\
\hline 22 & 0,2555 & 0,2696 & 1,1049 & 0,1741 & 2,54 \\
\hline 23 & 0,26 & 0,2753 & 2,201 & $-1,3376$ & 3,64 \\
\hline 24 & 0,1796 & 0,3173 & 2,4503 & $-2,0276$ & 3,44 \\
\hline 25 & 0,0137 & 0,5756 & 12,27 & $-24,03$ & 4,11 \\
\hline 26 & 0,2466 & 0,2588 & 1,9956 & $-1,5044$ & 3,03 \\
\hline 27 & 0,1766 & 0,356 & 2,0506 & $-0,7016$ & 3,69 \\
\hline 28 & 0,1986 & 0,3257 & 2,084 & $-0,7332$ & 3,87 \\
\hline 29 & 0,2797 & 0,2832 & 1,6027 & 0,2078 & 3,76 \\
\hline 30 & 0,7791 & 0,1596 & 2,1548 & $-1,1347$ & 3,84 \\
\hline 31 & 0,1916 & 0,3119 & 2,3987 & $-1,8934$ & 3,45 \\
\hline 32 & 0,1855 & 0,3219 & 1,7557 & $-0,413$ & 3,47 \\
\hline 33 & 0,6046 & 0,1652 & 2,0359 & $-1,6717$ & 2,92 \\
\hline 34 & 0,9693 & 0,148 & 2,3641 & $-1,3374$ & 4,00 \\
\hline 35 & 0,1535 & 0,3202 & 2,244 & $-2,0975$ & 2,87 \\
\hline 36 & 0,2826 & 0,2695 & 1,8719 & $-1,0163$ & 3,06 \\
\hline 37 & 0,3131 & 0,266 & 2,0246 & $-1,2021$ & 3,18 \\
\hline 38 & 0,1761 & 0,3034 & 1,7278 & $-0,5308$ & 3,41 \\
\hline 39 & 0,0431 & 0,5291 & 0,8146 & 0,4313 & 2,05 \\
\hline 40 & 0,1293 & 0,3702 & 4,062 & $-5,8447$ & 2,71 \\
\hline 41 & 0,106 & 0,3911 & 4,7586 & $-7,589$ & 2,04 \\
\hline 42 & 0,0478 & 0,5095 & 1,428 & 0,1701 & 3,18 \\
\hline 43 & 0,076 & 0,4475 & 2,4796 & $-1,871$ & 3,44 \\
\hline 44 & 0,1029 & 0,3904 & 2,9485 & $-3,8349$ & 2,27 \\
\hline 45 & 0,0489 & 0,502 & 1,2158 & 0,3301 & 2,88 \\
\hline 46 & 0,0838 & 0,4266 & 1,6601 & $-0,6801$ & 2,82 \\
\hline 47 & 0,0589 & 0,4826 & 1,5004 & $-0,3981$ & 2,71 \\
\hline 48 & 0,1163 & 0,3848 & 4,3402 & $-6,2823$ & 2,95 \\
\hline 49 & 0,1011 & 0,4068 & 1,9572 & $-1,3698$ & 2,72 \\
\hline 50 & 0,0919 & 0,4107 & 4,5739 & $-6,6004$ & 3,30 \\
\hline
\end{tabular}

Tabela 5: Ponto de interseção das Funções Exponencial e Logarítmica de cada uma das 50 Turmas Analisadas

Os pontos de interseção listados na última coluna da Tabela 5, devidamente tratados com auxílio estatístico de medidas de dispersão, levam a um resultado melhor apresentado para o ponto, ou região, que delimita os valores do Fator $\beta$ para alunos de "Alto" e "Muito Alto" desem- penho.

A partir da Variância (S) ou desvio quadrático médio da média, no caso $S=0,34$, define-se o Desvio Padrão $(\sigma)$ (Equação 9): 
$\sigma=\sqrt{S}=0,58$

Então, o valor mais provável, em que se encontra o ponto de interseção das curvas exponencial e logarítmica, é mais bem representado por:

$$
\begin{gathered}
X=3,20 \pm 0,58 \text { ou } \\
2,62 \leq X \leq 3,78
\end{gathered}
$$

Esses valores de $\mathrm{X}$ representam um intervalo de possibilidades para a escolha do Fator $\beta$ que demarca o início da classificação dos alunos com "Alto" e "Muito Alto" desempenho.

\subsection{Classificação de Desempenho do Aluno em Função do Fator $\beta$}

O estabelecimento dos limites do Fator $\beta$ em relação à Escala de Desempenho: Muito Alto, Alto, Médio, Baixo

\begin{tabular}{|c|c|c|c|c|c|}
\hline $\begin{array}{l}\text { Escala de } \\
\text { Desempenho }\end{array}$ & 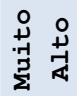 & 品 & 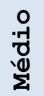 & 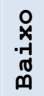 & 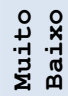 \\
\hline Fator $\beta$ & $\begin{array}{l}\infty \\
\sim \\
\dot{n} \\
\wedge \\
\infty\end{array}$ & $\begin{array}{l}\infty \\
\dot{n} \\
\dot{m} \\
v \\
\infty \\
v \\
v \\
v \\
j\end{array}$ & $\begin{array}{l}\tilde{b} \\
j \\
v \\
0 \\
v 1 \\
0 \\
0 \\
0\end{array}$ & $\begin{array}{l}\circ \\
\text { a } \\
0 \\
v \\
a \\
v 1 \\
\circ \\
\dot{m} \\
0\end{array}$ & $\begin{array}{l}0 \\
m \\
0 \\
v \\
0 \\
\text { vl } \\
0\end{array}$ \\
\hline
\end{tabular}
e Muito Baixo é apresentado na Tabela 6.

Tabela 6: Escala de Desempenho e Intervalos do Fator $\beta$

A partir da definição do intervalo de valores $2,62 \leq X$ $\leq 3,78$ na seção anterior, conjugada com análises e observações empíricas dos alunos obtidas diretamente a partir de seus desempenhos e comportamentos na sala de aula virtual, resolveu-se adotar semelhante intervalo para a classificação de alunos com desempenho "Alto", 2,62 $\leq$ Fator $\beta<3,78$, e o limite superior desse intervalo como o valor limítrofe a partir do qual se espera encontrar os alunos de "Muito Alto" desempenho, Fator $\beta \geq 3,78$, ou seja, alunos de expansivo espaço emocional e em plena fase de florescimento para as aprendizagens, que no Modelo Meta Learning de Losada, significa ultrapassar a Losada Line (taxa $\mathrm{P} / \mathrm{N}=2,90$ ) ou atingir a dinâmica dos complexores.

Espera-se que, acima do valor superior desse intervalo (Fator $\beta \geq 3,78$ ), o aluno atinja o domínio pleno das conceituações do objeto do conhecimento e se torne 'um outro mais capaz', elemento indispensável para o desenvolvimento e aprendizagem na teoria socio-histórica de Vigotski.

As ações de mediação desse 'outro mais capaz' podem auxiliar os demais a atingirem graus mais elevados de aprendizagem e, juntamente com o Professor/Tutor, pode ser um a mais a intervir intencionalmente na dinâmica da Zona de Desenvolvimento Proximal (ZDP), 1998a, b), visto que o que em determinado momento é potencial, em outro se transforma em real e, desta forma, a dinâmica da aprendizagem fica estabelecida.

Os demais intervalos, delimitados pelos valores do Fator $\beta$, para a classificação dos alunos quanto ao seu grau de desempenho em Médio, Baixo e Muito Baixo, apresentados na Tabela 6 , não foram determinados exclusivamente por faixas de notas. Esses intervalos são o resultado de observações empíricas da qualidade da participação, comportamento e rendimento dos alunos no curso, auxiliadas pelas análises dos gráficos das 50 turmas.

Observa-se também uma correlação dos limites dessas taxas com os limites estabelecidos por Losada [23] para equipes de médio e baixo desempenho apresentados em suas observações empíricas e comprovadas pela aplicação do Modelo Meta Learning.

É possível encontrar nos dados até então analisado alunos com desempenho "Alto" e com nota média inferior a outro de desempenho "Médio". A observação desses dados reafirmam a natureza qualitativa e o caráter da nãolinearidade do Fator $\beta$.

\section{Conclusões}

O presente trabalho apresentou um modelo de avaliação processual que inclui, simultaneamente, tanto o caráter quantitativo como o qualitativo do processo de avaliação. A utilização deste modelo representa uma alternativa relativamente às limitações e dificuldades impostas pela modalidade de EaD online.

O ambiente de sala de aula, seja online ou presencial, é um campo de incertezas e imprevisibilidades e, portanto, insere-se em uma dinâmica complexa. Avaliar, então, exige práticas pedagógicas diferenciadas e emergentes voltadas para incitar a vontade de aprender e de se autoorganizar.

Nesse sentido, o Fator $\beta$ busca, ao aliar-se à lógica formativa da avaliação, servir de indicador qualitativo e regulador da aprendizagem, bem como proporcionar uma nova métrica pedagógica não-linear e aberta, não fixada por sistema de notas definidas por escalas delimitadas em intervalo fechado.

Ao longo de seu processo de formação, o aluno poderá consultar seus Vetores-Aprendizagem, ou seus LV, analisar o seu rendimento, em termos de notas, e seu desempenho, por meio da taxa positividade/negatividade expressa pelo Fator $\beta$, o que poderá colaborar para sua autorregulação e aprendizagem. 
No modelo proposto, o Fator $\beta$ exprime qualitativamente o desempenho do aluno e pode ser aplicado para diferenciar alunos com notas finais iguais ou próximas, assim como auxiliar a traçar critérios para as tomadas de decisão de condições de aprovação do aluno ao final de um curso.

Um exemplo para este último caso é analisar a eventual possibilidade de aprovação de um aluno que não atingiu a nota mínima, mas cujo valor do Fator $\beta$ é superior ao valor médio obtido pelo grupo ( $\overline{\text { Fator } \beta}$ ) podendo até mesmo ser maior que o Fator $\beta$ de alunos aprovados.

Uma outra possibilidade seria usar o Fator $\beta$ como parâmetro para aprovação em um curso no lugar de notas de zero a dez. Por exemplo, caso um aluno tenha atingido o desempenho médio, estará aprovado, o que pode ser aplicado para currículos baseados em habilidades e competências.

Por fim, tratando a aprendizagem como um processo dinâmico e complexo, a ela associam-se desempenho, esforço, colaboração e interação. Por isso, ao conjunto desses atributos, relaciona-se o Fator $\beta$ como uma grandeza não-linear, propondo-se quantificar tais atributos, de maneira que eles possam contribuir na avaliação final das transformações e das complexidades que envolvem o ato de aprender.

$\mathrm{O}$ sujeito que aprende, à semelhança de um sistema aberto, pode se auto-organizar e se modificar. O Modelo LV e a métrica Fator $\beta$ representam uma alternativa a ser utilizada, na forma de quantificadores dos caminhos seguidos, para expressar qualitativamente as dinâmicas não-lineares decorrentes do ato de aprender.

Como trabalhos futuros, para um modelo de educação que vem sendo enriquecido com características como a personalização das aprendizagens e a flexibilização de processos, propõem-se investigar como o Fator $\beta$ pode colaborar para as funções formativa, diagnóstica e somativa da avaliação, bem como a sua influência efetiva nos alunos enquanto métrica não-linear frente aos sistemas tradicionais de notas linearmente atribuídas de zero a dez.

\section{Referências}

[1] L. Vygotsky. Pensamento e Linguagem. Tradução Jefferson Luiz Camargo, revisão técnica José Cipolla Neto. São Paulo: Ed. Martins Fontes, 1998.

. A formação social da mente: O desenvolvimento dos processos psicológicos superiores. Organizadores Michael Cole et al., tradução José Cipolla Neto, Luís Silveira Menna Barreto, Solange Castro Afeche. São Paulo: Ed. Martins
Fontes, 1998.

[3] A. Zabala. A Prática Educativa: como ensinar. Trad. Ernani F. da F. Rosa. Porto Alegre: ArtMed, 1998.

[4] P. Perrenoud. Avaliação: da excelência à regulação das aprendizagens entre duas lógicas. Porto Alegre: Artes Médicas, 1999.

[5] J. Hoffmann. Pontos e Contrapontos: do pensar ao agir em avaliação. Porto Alegre: Mediação, 1998.

[6] Brasil (2007). Referenciais de Qualidade para Educação Superior a distância. Ministério da Educação. Secretaria de Educação a distância. Extraído em 20 Junho de 2007 de http://portal.mec.gov.br/seed/arquivos/pdf/refere nciaisead.pdf

[7] M. S. S. Lopes. Avaliação da aprendizagem em atividades colaborativas em $\mathrm{EaD}$ viabilizada por um fórum categorizado. Dissertação de Mestrado, Instituto de Matemática, Universidade Federal do Rio de Janeiro, Fev. 2007.

[8] M. Silva. O fundamento comunicacional da avaliação da aprendizagem na sala de aula online. Em Marco Silva, Edméa Santos (orgs.). Avaliação da aprendizagem em educação online. São Paulo: Edições Loyola, 2006.

[9] L. A. S. Romani. Intermap: ferramenta para visualização da interação em ambientes de educação a distância na web. Dissertação de Mestrado, Instituto de Computação, Universidade Estadual de Campinas, Dez. 2000.

[10] J. C. T. Silva, J. R. Fernandes. Amon-Ad: um agente inteligente para avaliação de aprendizagem em ambientes baseados na web. Comunicação apresentada no VI Workshop de Informática na Escola, Curitiba, 2000.

[11] D. Musa, J. Oliveira, R. Vicari. Agente para auxílio à avaliação de aprendizagem em ambientes de ensino na Web. Comunicação apresentada no VII Workshop de Informática na Escola, Fortaleza, 2001.

[12] D. R. Silva, W. P. Seno, M. T. P. Vieira. Acompanhamento do aprendizado em educação a distância com uso de data mining. Comunicação apresentada na Conferência Latinoamericana de Informática, Mérida, Venezuela, 2001.

[13] H. Rocha. O ambiente TelEduc para educação à distância baseada na web: princípios, funcionali- 
dades e perspectivas de desenvolvimento. Em Moraes, M. C. (Org). Educação à Distância: Fundamentos e Práticas. pp. 197- 212.Campinas, SP: Unicamp/Nied, 2002.

[14] R. L. Lachi. Chapa: Um agente de interface para ferramentas de bate-papo em ambientes de ensino a distância na web. Dissertação de Mestrado, Instituto de Computação, Universidade Estadual de Campinas, Maio 2003.

[15] T. B. Ferreira. Gerenciador de Avaliações: Uma Ferramenta de Auxílio à Avaliação Formativa para o Ambiente de Educação a Distância TelEduc. Dissertação de Mestrado, Instituto de Computação, Universidade Estadual de Campinas, Dez. 2003.

[16] J. C. T. Silva, J. F. S. Araujo, J. R. Fernandes et al. AMon-Chat: um agente de interface para auxiliar na avaliação de aprendizagem baseada na Web. Comunicação apresentada no IX Workshop sobre Informática na Escola, Campinas, 2003.

[17] M. A. Gerosa, H. Fuks, C. J. P. Lucena. Estruturação e categorização de mensagens em ferramentas de comunicação textuais assíncronas. Comunicação apresentada em World Congress on Engineering And Technology Education WCETE'2004, Santos, São Paulo, Brasil, 2004.

[18] C. E. Alexakos, K. C. Giotopoulos, E. J. Thermogianni et al. Computational intelligence assessment agents. Proceedings of World Academy of Science, Engineering And Technology, v.13, 2006.

[19] J. L. Otsuka. Modelo de suporte à avaliação formativa baseado em sistemas multiagentes para ambientes de EaD. Tese de Doutorado, Instituto de Computação, Universidade Estadual de Campinas, Agt. 2006.

[20] C. Romero, S. Ventura. Educational data mining: A survey from 1995 to 2005. Expert Systems with Applications 33, pp. 135 - 146, 2007. Extraído em 20 Maio, 2010 de http://www.ecst.csuchico.edu/ juliano/csci693/P resentations/2008w/Materials/Lobban/DOCS/educational _data_mining.pdf

[21] C. Romero, S. Ventura, E. García. Data mining in course management systems: Moodle case study and tutorial. Computers and Education, 51 (1), pp. 368-384, 2008.

[22] G. L. Sales, G. C. Barroso, J. M. Soares et al.
Indicadores de aprendizagem Learning Vectors: uma aplicação em fóruns do ambiente virtual Moodle. Em TICAI 2008: TICs para a Aprendizagem da Engenharia. Carlos Vaz de Carvalho, Martín Llamas Nistal e Ricardo Silveira (orgs.). pp. 77-82. CIEEE, Sociedade de Educação: Capítulos Espanhol e Portugués. Extraído em 18 Dezembro, $2009 \quad$ de http://romulo.det.uvigo.es/ticai/libros/2008/2008 /TICAI_2008_Cap11.pdf

[23] M. Losada. The complex dynamics of high performance teams. Mathematical and Computer Modelling, v. 30, n. 9, pp. 179-192, 1999.

[24] M. Losada, E. Heaphy. The role of positivity and connectivity in the performance of business teams: A nonlinear dynamics model. American Behavioral Scientist, vol. 47, $\mathrm{n}^{\circ}$ 6, pp. 740-765, 2004.

[25] B. L. Fredrickson, M. Losada. Positive affect and the complex dynamics of human flourishing. American Psychologist, v. 60, n. 7, pp. 678-686, 2005.

[26] G. L. Sales, G. C. Barroso, J. M. Soares. Learning Vectors (LV): um instrumento automatizado de avaliação para suporte a aprendizagem em EaD. Revista Novas Tecnologias na Educação, v. 6, n. 1, 2008.

[27] G. L. Sales. Learning Vectors: Um Modelo de Avaliação da Aprendizagem em EaD Online Aplicando Métricas Não-Lineares. Tese de Doutorado. Programa de Pós-Graduação em Engenharia de Teleinformática. Universidade Federal do Ceará, Nov. 2010.

[28] W. H. Rice. Moodle e-learning course development. A complete guide to successful learning using Moodle. Birmingham: Packt Publishing, 2006.

[29] A. Filatro. Design instrucional na prática. São Paulo: Pearson Education do Brasil, 2008. 